\title{
COVID-19-like symptoms and their relation to SARS-CoV-2 epidemic in children and adults of an Italian birth cohort
}

\section{Maja Popovic ( $\nabla$ maja.popovic@unito.it)}

Cancer Epidemiology Unit, Department of Medical Sciences, University of Turin, and CPO Piemonte, Turin, Italy

\section{Chiara Moccia}

Cancer Epidemiology Unit, Department of Medical Sciences, University of Turin, and CPO Piemonte, Turin, Italy

Elena Isaevska

Cancer Epidemiology Unit, Department of Medical Sciences, University of Turin, and CPO Piemonte, Turin, Italy

\section{Giovenale Moirano}

Cancer Epidemiology Unit, Department of Medical Sciences, University of Turin, and CPO Piemonte, Turin, Italy

\section{Costanza Pizzi}

Cancer Epidemiology Unit, Department of Medical Sciences, University of Turin, and CPO Piemonte, Turin, Italy

\section{Daniela Zugna}

Cancer Epidemiology Unit, Department of Medical Sciences, University of Turin, and CPO Piemonte, Turin, Italy

\section{Franca Rusconi}

Unit of Epidemiology, Meyer Children's University Hospital, Florence, Italy

\section{Franco Merletti}

Cancer Epidemiology Unit, Department of Medical Sciences, University of Turin, and CPO Piemonte, Turin, Italy

\section{Milena Maule}

Cancer Epidemiology Unit, Department of Medical Sciences, University of Turin, and CPO Piemonte, Turin, Italy

\section{Lorenzo Richiardi}

Cancer Epidemiology Unit, Department of Medical Sciences, University of Turin, and CPO Piemonte, Turin, Italy

\section{Research Article}

Keywords: COVID-19, SARS-CoV-2, symptoms, Italy, sensitivity, children, adults, prevalence, NINFEA

Posted Date: November 10th, 2020

DOI: https://doi.org/10.21203/rs.3.rs-34027/v2

License: @) (i) This work is licensed under a Creative Commons Attribution 4.0 International License. Read Full License 


\section{Abstract}

Background A number of cases positive for SARS-CoV-2 escape surveillance systems, especially in the first epidemic waves and/or when the number of cases becomes too large to allow complete diagnostic coverage.

Methods During the first SARS-CoV-2 epidemic wave hitting Italy in the spring 2020, mothers participating in an Italian NINFEA birth cohort were invited to complete an online questionnaire on COVID-19-like symptoms in the household. We estimated the population prevalence of COVID-19-like symptoms in children and adults, assessed their geographical correlation with the cumulative number of COVID-19 cases by province, analysed their clustering within families, and estimated their sensitivity, positive predictive value (PPV) and negative predictive value (NPV) for COVID-19 diagnosis in individuals tested for SARS-CoV2.

Results Information was collected on 3184 households, 6133 adults, and 5751 children. In the period March-April 2020, 55.4\% of the NINFEA families had at least one member with at least one COVID-19-like symptom. There was a strong geographical correlation between the population cumulative incidence of COVID-19 and the prevalence of muscle pain, fatigue, low-grade fever, and breathing difficulties in adults (Spearman's rho $\geq 0.70$ ). Having at least one family member with a COVID-19 diagnosis, compared with none tested for SARS-CoV-2, was associated with an increased prevalence ratio (PR) of almost all COVID-19-like symptoms in adults, and only of low-grade fever (37-37.5 ${ }^{\circ}$; PR 5.27; 95\% confidence intervals: 2.37 to 11.74 ) and anosmia/dysgeusia in children. Among adults with COVID-19 diagnosis, fatigue, muscle pain, and fever had a sensitivity $\geq 70 \%$. In individuals tested for SARS-CoV-2, with a $16.6 \%$ prevalence of COVID-19, breathing difficulties and nausea/vomiting had the highest PPVs, with point estimates close to $60 \%$, and with NPVs close to $90 \%$.

Conclusions The geographical prevalence of COVID-19-like symptoms in adults may inform on local disease clusters, while certain symptoms in family members of confirmed COVID-19 cases could help identify the intra-familial spread of the virus and its further propagation in the community. Low-grade fever is frequent in children with at least one household member with COVID-19 and possibly indicates child infection.

\section{Introduction}

It is recognized that a substantial number of cases of severe acute respiratory syndrome coronavirus 2 (SARS-CoV-2) remain undiagnosed, escaping surveillance systems. These mainly include asymptomatic individuals and patients with mild or subclinical presentations that likely represent the majority of patients, especially among children [1, 2]. Reported symptoms of coronavirus disease 2019 (COVID-19) include fever, cough, sore throat, shortness of breath, myalgia, fatigue, diarrhoea, nausea or vomiting, and headache [3, 4]. In particular, loss of smell (anosmia) and taste (dysgeusia) have been reported to be highly suggestive of SARS-CoV-2 infection $[5,6]$.

Even if symptoms of COVID-19 play an important role in seeking health care assistance or self-isolation and informing the testing and diagnostic workflow [7], their population-based prevalence has been less investigated. Likewise, it is unclear whether this prevalence may inform on the spread of the disease beyond surveillance systems. This is particularly true in children, who rarely have a severe form of the disease, and are thus seldom tested for SARS-CoV-2 outside the investigation of clusters, for example at schools. As a consequence, children represent a rather small proportion of all reported diagnosed COVID-19 cases (e.g. children 0-9 years $3.2 \%$ in Italy as of October $27^{\text {th }} 2020$ ) [8]; but may play an important role in the spread of the disease and contribute to herd immunity. Based on the preliminary results of an Italian national seroprevalence study conducted in May - June 2020 [9], it can be estimated that in the age group 0-19 years out of 100 cases only 2.5 were actually diagnosed, while the same estimate in adults ( $\geq 20$ years) was $18.9 \%$.

Some web-based surveys have been launched to explore, among other aims, the population prevalence of COVID-19-like symptoms. Many of these surveys, however, recruit volunteers online with no information on the response proportion. Thus they are prone to selection bias when aiming to estimate the population prevalence, as individuals with specific symptoms, or who experienced those symptoms in the recent past, may be more or less likely to volunteer than asymptomatic individuals.

Page 2/13 
Additionally, some ad-hoc web-based cohorts have been established, in which participants volunteer to report their symptoms on a regular basis [10]. This design is less affected by selection bias as participants may be enrolled before the onset of the symptoms.

The first confirmed autochthonous COVID-19 case in Italy was identified on February 21, 2020. To explore the relationship between reported COVID-19-like symptoms and the registered COVID-19 diagnoses in children and adults during the first

epidemic wave in Italy, on April $7^{\text {th }}$, we invited the participants of an Italian NINFEA (Nascita e Infanzia: gli Effetti dell'Ambiente; Birth and Childhood: Effects of the Environment) birth cohort involving women recruited during pregnancy between 2005 and 2016 and their families to complete a short online questionnaire on COVID-19, with a particular focus on symptoms. The questionnaire closed on April $20^{\text {th }}$, after 13 days. In this paper, we (i) explore the geographical correlation between the population prevalence of COVID-19-like symptoms in the adults and children of the cohort during the initial phases of the epidemic and the cumulative number of new SARS-CoV-2 positive cases reported by the Surveillance System; (ii) analyse the clustering of symptoms within families with or without a member who tested negative for SARS-CoV-2 or was diagnosed with COVID-19; and (iii) estimate the sensitivity, positive and negative predictive values for COVID-19-like symptoms in the tested individuals of the NINFEA population.

\section{Methods}

\section{Study design and population}

The NINFEA study is an Italian internet-based mother-child cohort (www.progettoninfea.it) set up to investigate the influence of early-life exposures on later childhood and adulthood health. Between 2005 and 2016, approximately 7,500 pregnant women were recruited by completing the baseline questionnaire, and the children are currently followed up with questionnaires completed by mothers at 6 and 18 months after delivery and when the children turn 4, 7, 10 and 13 years. Details on the cohort have been published before [11-14].

\section{COVID-19 survey}

Women who completed at least the first NINFEA follow-up questionnaire (when the child was 6 months old, N=5879) were invited to complete an anonymous online questionnaire to assess the prevalence of COVID-19-like symptoms in their households. A first e-mail was sent out on April 7, 2020, approximately 5 weeks after the Italian government imposed national lockdown. The questionnaire remained open for 13 days (until April $20^{\text {th }}$ ) and, during this period, two reminder e-mails were sent.

The questionnaire consisted of background information on respondents' age, sex, year of recruitment into the NINFEA cohort, educational level, province, region and area of residence, and the source from which information on COVID-19 was sought. The second part of the questionnaire asked about family composition and sex and age of family members; and included a checklist of COVID-19-like symptoms since the day of the first reported case in Italy (February 21, 2020), and in the last week, for each close family member (mother, partner, and each child <18 years old). The symptoms included: nasal congestion, lowgrade fever $\left(37.0-37.5^{\circ} \mathrm{C}\right)$, fever $\left(>37.5^{\circ} \mathrm{C}\right)$, cough, sore throat, nausea/vomiting, diarrhea, muscle pain, and fatigue. Questions on breathing difficulties and loss of taste or smell (anosmia/dysgeusia) were introduced a few days after launching the questionnaire, and are available for $64.2 \%$ of the respondents. We also collected information on SARS-CoV- 2 testing (using nasopharyngeal swabs and real-time reverse transcription polymerase chain reaction [RT-PCR]) and COVID-19 diagnosis for each of the close family members and other people living in the same household.

\section{Administrative data}

The population cumulative incidence of new SARS-CoV-2 positive cases until April 7, 2020 by province was obtained from national Surveillance System data available at the website of the Italian Ministry of Health/Civil Protection Department [15] and province population size (all residents as of January 1, 2020) obtained from the Italian National Institute of Statistics [16]. 


\section{Statistical analyses}

To account for survey non-response, weights for each respondent were calculated using iterative proportional fitting [17], allowing the distribution of the survey variables to closely resemble the known NINFEA population margins. The weights were calculated using the following maternal characteristics: age ( $<35$ years, 35-40 years, 40-45 years, $45-50$ years and $\geq 50$ years), educational level (low - primary school or less, medium - secondary school, and high - university degree or higher), and period of enrolment in the NINFEA study (2005-2008, 2009-2012, 2013-2016).

Using the estimated weights, descriptive statistics were calculated for sociodemographic characteristics, cumulative symptoms, SARS-CoV-2 testing and COVID-19 diagnosis separately for children $<6$ years, children 6-18 years, and adults.

To explore the geographical correlation between the prevalence of COVID-19-like symptoms and the population cumulative number of newly reported SARS-CoV-2 cases, we first estimated the predicted probability of each symptom given the province of residence using weighted logistic regression models and accounting for family clusters. These analyses were performed only in provinces with more than 50 study subjects (Alessandria, Asti, Cuneo and Torino, in Piedmont; Milan, in Lombardy; Arezzo, Lucca, and Florence, in Tuscany; Rome, in Lazio). The predicted probabilities were correlated to the corresponding province cumulative incidences per 1000 inhabitants (as of April 7, 2020), using Spearman's rank correlation coefficients. These analyses were performed separately in 6 to 18-year-old children, in adults, and at the household-level.

To analyse the clustering of symptoms within families exposed to SARS-CoV-2 we used a three-level exposure variable defined as: i) no family/household member tested for SARS-CoV-2, ii) at least one tested member but none with COVID-19, and iii) at least one member being diagnosed with COVID-19. This exposure was analysed in association with the presence of each COVID-19-like symptom, separately in 6 to 18-year-old children and in adults. We estimated the prevalence ratios, with corresponding 95\% confidence intervals (Cls), using weighted Poisson regression models with cluster-robust standard errors to account for the family structure. Models were adjusted for sex, age, maternal educational level (low, medium, high), family size (2 members, 3 members, 4 members, and $\geq 5$ members), area of residence (urban, suburban, and rural), region of residence (Piedmont, Tuscany, Lombardy, other regions of Northern Italy, Central Italian regions, Southern Italian regions, and abroad), and maternal age (for analysis of children). A sensitivity analysis was performed by excluding all reported COVID-19 cases.

For each symptom, we calculated its sensitivity for COVID-19 among NINFEA adults and its positive (PPV) and negative (NPV) predictive values among NINFEA adults tested for SARS-CoV-2. As more than $60 \%$ of the NINFEA participants come from Piedmont, one of the Italian regions most affected by COVID-19, we repeated the analyses restricted to Piedmont residents. For these, we also estimated the population PPV of each symptom.

All analyses were conducted using Stata version 15.1 (College Station, Texas, USA).

\section{Results}

The descriptive characteristics of the study population are shown in Table 1. A total of 3184 NINFEA participants responded to the COVID-19 survey, $54.2 \%$ of the total population invited. Their characteristics, including age, region of residence and year of enrolment in the NINFEA cohort were similar to those of the NINFEA cohort at baseline. Information was collected on 3184 households, 6133 adults, and 5751 children.

Table 2 reports the weighted prevalence of COVID-19-like symptoms during the study period, separately for children aged $<6$ years, children aged 6-18 years, adults, and at the household level. More than half of the families (55.4\%) had at least one member with at least one COVID-19-like symptom. The most prevalent symptoms in adults were: fatigue (16.5\%), sore throat (14.5\%), cough (13.8\%), nasal congestion (13.2\%), and muscle pain (11.4\%). Among children, the most common symptoms were nasal congestion, cough, and fever $>37.5^{\circ} \mathrm{C}$. There was no evidence of an association between time to response and the prevalence of symptoms in adults or children (all p-values $>0.05$ ). 
A total of $169(2.6 \%)$ adults and $14(0.2 \%)$ children were tested for SARS-CoV-2 using nasopharyngeal swabs. Twenty-eight adults (16.6\%) tested positive and 2 additional subjects reported COVID-19 diagnosis without RT-PCR COVID-19 test. No information was available on diagnostic criteria for these two subjects. Thus, a total of 30 NINFEA adults $(0.5 \%), 20$ females and 10 males, were diagnosed with COVID-19. Among children, only one 5-year-old child, with both parents positive, tested positive for COVID-19.

Geographical correlation between population COVID-19 incidence and prevalence of COVID-19-like symptoms, testing for SARSCoV-2 and COVID-19 diagnosis in the NINFEA population

We observed a strong geographical correlation between the population cumulative incidence of SARS-CoV-2 cases as of April $7^{\text {th }} 2020$ and the prevalence of COVID-19 diagnosis among NINFEA participants (Spearman's rho 0.80, based only on 4 provinces), and a low correlation with SARS-CoV-2 testing prevalence (Table 3, Additional File 1, Figure A1).

There was a high correlation between the population SARS-CoV-2 cumulative incidence and the prevalence of muscle pain, fatigue, low-grade fever and breathing difficulties in the NINFEA adult population, especially in men (all Spearman's rho $\geq 0.70$,

Table 3, Additional File 1,Figures A2, and Table A1 for analyses stratified by sex). No evidence of correlation, with the exception of muscle pain and fatigue, was found in children (Table 3, Additional File, Figure A3).

Clustering of COVID-19-like symptoms within families that tested negative for SARS-CoV-2 and families diagnosed with COVID19

In 6 to 18-year-old children, we found an adjusted prevalence ratio of low-grade fever of 5.27 (95\% Cl: 2.37 ; 11.74) for having at least one family member with a COVID-19 diagnosis, compared with children with no family members tested for SARS-CoV-2. There was also a high prevalence ratio of anosmia/dysgeusia (25.5; 95\% Cl: 2.58; 252), based only on 2 exposed cases. There was no clear evidence of association with other symptoms (Table 4), including muscle pain and fatigue, the only symptoms in children showing a high ecological (province-level) correlation with the population SARS-CoV-2 cumulative incidence. However, muscle pain and fatigue in children were strongly associated with muscle pain and fatigue in their parents (data not shown), suggesting that these may just be proxies of the same symptoms in parents.

We found increased prevalence ratios of almost all COVID-19-like symptoms when comparing adults with at least one family member with a COVID-19 diagnosis with those whose household members were not tested for SARS-CoV-2 (Table 4).

Particularly high prevalence ratios were found for breathing difficulties (14.4; 95\% Cl: 7.98; 26.0), anosmia/dysgeusia (13.64; $95 \% \mathrm{Cl}: 7.34 ; 25.4)$, and fever $>37.5^{\circ} \mathrm{C}(8.68 ; 95 \% \mathrm{Cl}: 6.10 ; 12.3)$. Most of these associations remained after we excluded all reported COVID-19 cases to assess whether the observed prevalence ratios were due to the positive COVID-19 family member(s) (Table 4, last row).

Increased prevalence ratios, although of a lower magnitude, were observed when comparing adults with at least one family member who tested negative for SARS-COV-2 with adults from untested households. In children, conversely, having a family member who tested negative for SARS-CoV-2 was not associated with an increased prevalence of any of the symptoms.

Sensitivity, PPVs and NPVs of COVID-19-like symptoms in the adult NINFEA population

Table 5 shows sensitivity, PPVs and NPVs of COVID-19 diagnosis for COVID-19-like symptoms in adults tested for SARS-CoV-2. Sensitivities higher than $70 \%$ were observed for fatigue, fever $>37^{\circ} \mathrm{C}$, and muscle pain (Table 5).

The analyses restricted to the tested NINFEA Piedmont residents revealed similar PPVs as for the full cohort, with higher PPVs for breathing difficulties $(88.9 \% ; 95 \% \mathrm{Cl}: 68.4 ; 100.0)$ and the loss of taste or smell $(83.3 \% ; 95 \% \mathrm{Cl}: 53.5 ; 100.0)$. In the entire NINFEA Piedmont population, with a COVID-19 prevalence of $0.54 \%$ (Table 5, last column), breathing difficulties, anosmia/dysgeusia and fever $>37^{\circ} \mathrm{C}$ had the highest PPVs $(10.8 \%, 7.7 \%$, and $7.3 \%$, respectively).

\section{Discussion}


We used data obtained from the members of an ongoing cohort of Italian children and their family members, mainly from northern Italy, to study COVID-19-like symptoms in children and adults during the initial phases of the COVID-19 epidemic. In the 6-8 weeks since the first known autochthonous Italian COVID-19 case, more than a half of the interviewed families had at least one family member with at least one COVID-19-like symptom. Overall, adults reported a relatively high prevalence of fatigue, cough, sore throat, nasal congestion and muscle pain, while in children the most frequent symptoms included nasal congestion, cough and fever. While COVID-19-like symptoms were quite frequent, the prevalence of diagnosed COVID-19 in the cohort was $0.5 \%$ among adults, close to $0 \%$ among children, and $16.6 \%$ among adults tested for SARS-COV-2. This may suggest that COVID-19-like symptoms are in general not highly specific and/or that SARS-CoV-2 infection is underdiagnosed, especially in children. These two aspects were further explored in our study at an ecological and individual level.

Ecologically, there was a strong correlation between the prevalence of muscle pain, fatigue, low-grade fever and breathing difficulties in adults and the population cumulative number of SARS-CoV-2 cases. In children, a similar geographical correlation was found only for the prevalence of muscle pain and fatigue, which were likely driven by parental symptoms and possible differential reporting (i.e. parents with muscle pain more likely report muscle pain in their children). Consistent with other studies $[6,10,18,19]$, our findings suggest that monitoring the prevalence of COVID-19-like symptoms in adults, but not in children, may serve as an alert of changes in disease activity and may inform about local disease clusters.

It has been reported that most COVID-19 cases had either documented contact with an infected case or were part of family clusters [4, 20-23]. In a report based on 171 COVID-19-positive children, 90.1\% of cases came from COVID-19 positive families [4]. Here, we examined the prevalence of COVID-19-like symptoms in the presence of a family member with COVID-19. In children, exposure to COVID-19 within the family was associated with a strongly increased prevalence of low-grade fever (37.0$37.5^{\circ} \mathrm{C}$ ) and anosmia/dysgeusia, but with no other symptoms. This is consistent with previous findings that children are often asymptomatic [4, 24-25], but, when they are symptomatic, fever is the most frequent symptom, with a reported prevalence between $40 \%$ and $56 \%$ [4, 25-28]. It is possible that children from COVID-19 positive families have a mild presentation of the disease without receiving diagnosis and escaping the surveillance systems. Additionally, our finding was confined to low-grade fever, suggesting that in children low-grade fever may be more specific to SARS-CoV-2 infection than fever above $37.5^{\circ} \mathrm{C}$.

On the other hand, the analyses in adults showed a clear pattern of familiar symptom aggregation. Adults in households with at least one family member diagnosed with COVID-19 had a higher prevalence of almost all symptoms compared with adults with no family member tested for SARS-CoV-2. The same symptoms were also associated with SARS-CoV-2 negative testing in the household, suggesting that testing was also performed for symptoms caused by infectious diseases other than COVID-19. The most relevant symptoms in adults exposed to COVID-19 within the family included breathing difficulties, anosmia/dysgeusia, muscle pain, fatigue, cough and diarrhea. This is consistent with other studies reporting the patterns of symptoms in adults with COVID-19 [6, 25, 29,30]. Consistent with our results, loss of smell or taste has been reported to be one of the strongest predictors of COVID-19 [6,30]. The presence of these symptoms among adult family members of COVID-19 cases is suggestive of COVID-19 transmission within a family, and testing of symptomatic adults, and possibly children with low fever, is key to prevent further community transmission.

Although the presence of symptoms is one of the main indications for testing, especially when contact tracing is unable to cope with an increasing number of diagnosed cases, among tested individuals in the NINFEA population, only anosmia/dysgeusia and breathing difficulties reached a PPV above 80\% (in Piedmont residents, lower in the full population), and no symptom had a PPV of at least $90 \%$; similarly, only breathing difficulties, fatigue and muscle pain had an NPV close to $95 \%$. Finally, PPVs for SARS-CoV-2 positive testing in the population varied between $1 \%$ and $11 \%$, with an a priori probability of $0.5 \%$. These PPVs are the consequence of both the local testing approach and the PPV among tested individuals. COVID-19 testing practices in Italy differ across regional jurisdictions; they changed during the different phases of the outbreak, and differ across age groups. Our estimates of sensitivity and predictive values thus depend on these contextual variables, which may detract from their generalizability to other contexts

We surveyed the population of children and their family members who are participating in a web-based birth cohort established in 2005 and followed up for many years now. Therefore, our estimates are based on the well-known underlying population, and 
are less prone to selection bias due to outcome-driven participation. We had an approximately $55 \%$ response proportion to the COVID-19 survey in our study, but respondents were similar to non-respondents regarding baseline characteristics, and there was no evidence of an association between late response and the prevalence of symptoms.

Although we had no information on the temporal relationship between the onset of symptoms and diagnosis, the study period is a maximum of 6-8 weeks, and it is relatively unlikely that in such a short period, the symptoms could be due to other conditions. This is, indeed, one of the main strengths of our study which was able to focus on a relatively short time period during which the first wave of COVID-19 epidemic peaked in Italy, while the ability of the surveillance system to detect the cases was rather low due to lack of preparedness. All information collected in our study was reported by one member of the family on behalf of all members, possibly leading to misclassification. This is especially true for less severe symptoms (e.g., nasal congestion) with short duration, while we do not expect misclassification for hard variables such as SARS-CoV-2 swab testing and COVID-19 diagnosis.

\section{Conclusions}

We found that the population prevalence of certain symptoms may be relevant for the identification of future local disease clusters and that symptoms in family members of confirmed COVID-19 cases could help identify the intrafamilial spread of the virus and its further propagation in the community. Low-grade fever is frequent in children with at least one household member with COVID-19 and possibly indicates child infection.

\section{List Of Abbreviations}

$\mathrm{Cl}$ - Confidence Intreval

COVID-19 - Coronavirus disease 2019

NINFEA - Nascita e Infanzia: gli Effetti dell'Ambiente

NPV - Negative Predictive Value

PPV - Positive Predictive Value

PR - Prevalence Ratio

RT-PCR - Reverse Transcription Polymerase Chain Reaction

SARS-CoV-2 - Severe Acute Respiratory Syndrome CoronaVirus 2

\section{Declarations}

\section{Ethics approval and consent to participate}

The NINFEA study was approved by the Ethical Committee of the San Giovanni Battista Hospital and CTO/CRF/Maria Adelaide Hospital of Turin (project number 45) and all the participants gave informed consent at enrolment and after completing each study follow-up questionnaire. A specific amendment to the Ethical Committee was submitted for the COVID-19 survey. All procedures were conducted in accordance with the relevant guidelines and regulations.

\section{Consent for publication}

Not applicable.

\section{Availability of data and materials}


The dataset analysed during the current study is available from the corresponding author on reasonable request. The number of new SARS-CoV-2 positive cases until April 7, 2020 by province was obtained from national Surveillance System data (Italian Ministry of Health/Civil Protection Department) available in the GitHub repository, https://github.com/pcm-dpc/COVID-19, while the province population size was obtained from the website of Italian National Institute of Statistics, http://dati.istat.it/.

\section{Competing interests}

The authors declare that they have no competing interests.

\section{Funding}

The NINFEA study was partially funded by the Compagnia San Paolo Foundation, which had no role in the design of the study, collection, analysis, or interpretation of data.

\section{Authors' contributions}

All authors contributed to the conception and the design of the study. CM coordinated the acquisition of the data. MP, CM, and $\mathrm{El}$ analysed the data. All authors were involved in the data interpretation. MP and LR drafted the first version of the manuscript. All authors revised the manuscript critically for important intellectual content and all have approved the version to be submitted.

\section{Acknowledgements}

The authors are grateful to Paola Ivaldi, Sonia Barccelari, Fabio Saccona, Francesco Brunetti, Ugo Casalone, and to all the participants of the NINFEA cohort for their continuous contribution to the NINFEA cohort.

\section{Authors' information (optional)}

\section{References}

1. Nishiura H, Kobayashi T, Miyama T, Suzuki A, Jung SM, Hayashi K, et al. Estimation of the asymptomatic ratio of novel coronavirus infections (COVID-19). Int J Infect Dis. 2020;94:154-5.

2. Chan JF, Yuan S, Kok KH, To KK, Chu H, Yang J, et al.. A familial cluster of pneumonia associated with the 2019 novel coronavirus indicating person-to-person transmission: a study of a family cluster. Lancet. 2020;395(10223):514-23.

3. Wu Z, McGoogan, JM. Characteristics of and important lessons from the coronavirus disease 2019 (COVID-19) outbreak in China. JAMA. 2020;323(13):1239.

4. Lu X, Zhang L, Du H, Zhang J, Li YY, Qu J, et al. SARS-CoV-2 infection in children. N Engl J Med. 2020;382(17):1663-5.

5. Giacomelli A, Pezzati L, Conti F, Bernacchia D, Siano M, Oreni L, et al. Self-reported olfactory and taste disorders in patients with severe acute respiratory coronavirus 2 infection: a cross-sectional study. Clin Infect Dis. 2020;71(15):889-90.

6. Menni C, Valdes AM, Freidin MB, Sudre CH, Nguyen LH, Drew DA, et al. Real-time tracking of self-reported symptoms to predict potential COVID-19. Nat Med. 2020;26(7):1037-40.

7. World Health Organization. Laboratory testing strategy recommendations for COVID-19: interim guidance, 21 March 2020. https://apps.who.int/iris/handle/10665/331509 (2020). Accessed 09 Nov 2020.

8. Italian National Health Institute (Istituto Superiore di Sanità). Epidemia COVID-19. Aggiornamento nazionale 27 ottobre 2020 - ore 11:00. https://www.epicentro.iss.it/coronavirus/bollettino/Bollettino-sorveglianza-integrata-COVID-19_27ottobre-2020.pdf (2020). Accessed 05 Nov 2020.

9. Italian National Health Institute (Istituto Superiore di Sanità). Primi risultati dell'indagine di di sieroprevalenza sul SARSCoV-2. https://www.istat.it/it/files/2020/08/ReportPrimiRisultatilndagineSiero.pdf (2020). Accessed 09 Nov 2020.

10. Drew DA, Nguyen LH, Steves CJ, Menni C, Freydin M, Varsavsky T, et al. Rapid implementation of mobile technology for real-time epidemiology of COVID-19. Science. 2020;368(6497):1362-7. 
11. Richiardi L, Baussano I, Vizzini L, Douwes J, Pearce N, Merletti F, NINFEA cohort. Feasibility of recruiting a birth cohort through the Internet: the experience of the NINFEA cohort. Eur J Epidemiol. 2007;22(12):831-7.

12. Firestone R, Cheng S, Pearce N, Douwes J, Merletti F, Pizzi C, et al. Internet-based birth-cohort studies: is this the future for epidemiology? JMIR Res Protoc. 2015;4(2):e71.

13. Blumenberg C, Zugna D, Popovic M, Pizzi C, Barros AJD, Richiardi L. Questionnaire breakoff and item nonresponse in webbased questionnaires: multilevel analysis of person-level and item design factors in a birth cohort. J Med Internet Res. 2018;20(12):e11046.

14. Bajardi P, Paolotti D, Vespignani A, Eames K, Funk S, Edmunds WJ, et al. Association between recruitment methods and attrition in Internet-based studies. PLoS One. 2014;9(12):e114925.

15. Presidency of the Council of Ministers. The Civil Protection Department. https://github.com/pcm-dpc/COVID-19 (2020). Accessed 22 Apr 2020.

16. Italian National Institute of Statistics (ISTAT). http://dati.istat.it/ (2020). Accessed 22 Apr 2020.

17. Battaglia MP, Frankel MR, Link MW. Improving standard poststratification techniques for random-digit-dialing telephone surveys. Survey Res Methods. 2008;21:11-9.

18. Bowyer R, Varsavsky T, Sudre CH, Murray B, Freidin M, Yarand D, et al. Geo-social gradients in predicted COVID-19 prevalence and severity in Great Britain: results from 2,266,235 users of the COVID-19 Symptoms Tracker app. Preprint at https://www.medrxiv.org/content/10.1101/2020.04.23.20076521v1 (2020). Accessed 27 Oct 2020.

19. Williams FMK, Freydin M, Mangino M, Couvreur S, Visconti A, Bowyer RCE, et al. Self-reported symptoms of covid-19 including symptoms most predictive of SARS-CoV-2 infection, are heritable. Preprint at https://www.medrxiv.org/content/10.1101/2020.04.22.20072124v2 (2020). Accessed 27 Oct 2020.

20. Tian S, Hu N, Lou J, Chen K, Kang X, Xiang Z, et al. Characteristics of COVID-19 infection in Beijing. J Infect. 2020;80(4):401-6.

21. Dong Y, Mo X, Hu Y, Qi X, Jiang F, Jiang Z, Tong S. Epidemiology of COVID-19 among children in China. Pediatrics. 2020;145(6):e20200702.

22. Grijalva CG, Rolfes MA, Zhu Y, McLean HQ, Hanson KE, Belongia EA, et al. Transmission of SARS-COV-2 infections in households - Tennessee and Wisconsin, April-September 2020. MMWR Morb Mortal Wkly Rep. 2020;69:1631-4.

23. Madewell ZJ, Yang Y, Longini Jr. IM, Halloran ME, Dean NE. Household transmission of SARS-CoV-2: a systematic review and meta-analysis of secondary attack rate. Preprint at https://www.medrxiv.org/content/10.1101/2020.07.29.20164590v1 (2020). Accessed 09 Nov 2020.

24. Tagarro A, Epalza C, Santos M, Sanz-Santaeufemia FJ, Otheo E, Moraleda C, Calvo C. Screening and severity of Coronavirus Disease 2019 (COVID-19) in children in Madrid, Spain. JAMA Pediatr. 2020:e201346. doi: 10.1001/jamapediatrics.2020.1346.

25. CDC COVID-19 Response Team. Coronavirus disease 2019 in children - United States, February 12-April 2, 2020. MMWR Morb Mortal Wkly Rep 2020;69:422-6.

26. Chen A, Huang J, Liao Y, Liu Z, Chen D, Yang C, et al. Differences in clinical and imaging presentation of pediatric patients with COVID-19 in comparison with adults. Radiol Cardiothorac Imaging. 2020;2:2. doi: 10.1148/ryct.2020200117

27. Qiu H, Wu J, Hong L, Luo Y, Song Q, Chen D. Clinical and epidemiological features of 36 children with coronavirus disease 2019 (COVID-19) in Zhejiang, China: an observational cohort study. Lancet Infect Dis. 2020;20(6):689-96.

28. de Souza TH, Nadal JA, Nogueira RJN, Pereira RM, Brandão MB. Clinical manifestations of children with COVID-19: A systematic review. Pediatr Pulmonol. 2020;55(8):1892-9.

29. Fu L, Wang B, Yuan T, Chen X, Ao Y, Fitzpatrick T, et al. Clinical characteristics of coronavirus disease 2019 (COVID-19) in China: A systematic review and meta-analysis. J Infect. 2020;80(6):656-65.

30. Zens M, Brammertz A, Herpich J, Südkamp N, Hinterseer M. App-based tracking of self-reported COVID-19 symptoms: analysis of questionnaire data. J Med Internet Res. 2020;22(9):e21956. 
Table 1. Descriptive statistics of the study population

\begin{tabular}{|c|c|c|}
\hline Characteristics & $\mathrm{N}^{1}$ & Weighted prevalence $(95 \% \mathrm{CI}) /$ Weighted mean $(\mathrm{SD})^{2}$ \\
\hline Total number of families & 3184 & 1 \\
\hline Total number parents & 6133 & I \\
\hline Total number of children ( $<18$ years) & 5751 & I \\
\hline \multicolumn{3}{|l|}{ Sex (parents) } \\
\hline Female & 3178 & $51.9(51.6 ; 52.2)$ \\
\hline Male & 2955 & $48.1(47.8 ; 48.4)$ \\
\hline \multicolumn{3}{|l|}{ Single parent } \\
\hline Yes & 235 & $7.6(6.7 ; 8.6)$ \\
\hline No & 2949 & $92.4(91.4 ; 93.3)$ \\
\hline \multicolumn{3}{|l|}{ Sex (children) } \\
\hline Female & 2788 & $48.9(47.6 ; 50.2)$ \\
\hline Male & 2917 & $51.1(49.8 ; 52.4)$ \\
\hline \multirow[t]{6}{*}{ Maternal age } & 3169 & $41.9(5.0)$ \\
\hline & 201 & $7.4(6.5 ; 8,5)$ \\
\hline & 746 & $24.1(22,6 ; 25,6)$ \\
\hline & 1160 & $36.8(35,1 ; 38,5)$ \\
\hline & 839 & $25.5(24,1 ; 27,1)$ \\
\hline & 223 & $6.2(5,4 ; 7,0)$ \\
\hline Paternal age & 2931 & $44.6(6.1)$ \\
\hline$<35$ years & 106 & $4.0(3.3 ; 4.8)$ \\
\hline $35-40$ years & 440 & $15.5(14.2 ; 16.9)$ \\
\hline 40-45 years & 911 & $31.3(29.6 ; 33.0)$ \\
\hline $45-50$ years & 894 & $30.4(28.7 ; 32.1)$ \\
\hline$\geq 50$ years & 580 & $18.9(17.5 ; 20.3)$ \\
\hline Child age & 5735 & $7.7(3.7)$ \\
\hline$<6$ years & 1671 & $29.0(27.7 ; 30.3)$ \\
\hline $6-18$ years & 4064 & $71.0(69.7 ; 72.3)$ \\
\hline \multicolumn{3}{|l|}{ Maternal educational level ${ }^{3}$} \\
\hline Low & 94 & $4.8(4.0 ; 5.9)$ \\
\hline Medium & 948 & $33.3(31.7 ; 35.1)$ \\
\hline High & 2128 & $61.9(60.1 ; 63.6)$ \\
\hline \multicolumn{3}{|l|}{ Family size } \\
\hline 2 members & 118 & $3.8(3.2 ; 4.5)$ \\
\hline 3 members & 875 & $27.0(25.5 ; 28.6)$ \\
\hline 4 members & 1629 & $51.5(49.4 ; 52.9)$ \\
\hline$\geq 5$ members & 562 & $18.1(16.8 ; 19.5)$ \\
\hline \multicolumn{3}{|l|}{ Number of children $<18$ years in the household } \\
\hline 1 child & 1032 & $32.0(30.4 ; 33.7)$ \\
\hline 2 children & 1808 & $56.8(55.1 ; 58.6)$ \\
\hline 3 children & 289 & $9.4(8.4 ; 10.5)$ \\
\hline 4 children & 55 & $1.8(1.4 ; 2.3)$ \\
\hline \multicolumn{3}{|l|}{ Residential area } \\
\hline Urban & 995 & $30.3(28.7 ; 31.9)$ \\
\hline Suburban & 1501 & $47.8(46.0 ; 49.5)$ \\
\hline Rural & 687 & $21.9(20.5 ; 23.4)$ \\
\hline \multicolumn{3}{|l|}{ Region of residence } \\
\hline Piedmont & 2055 & $64.0(62.3 ; 65.7)$ \\
\hline Tuscany & 640 & $20.6(19.2 ; 22.0)$ \\
\hline Lombardy & 141 & $4.43(3.8 ; 5.2)$ \\
\hline Other regions of Northern Italy & 160 & $5.2(4.4 ; 6.0)$ \\
\hline Central Italian regions & 85 & $2.6(2.1 ; 3.3)$ \\
\hline Southern Italian regions & 77 & $2.5(2.0 ; 3.1)$ \\
\hline Abroad & 26 & $0.8(0.5 ; 1.1)$ \\
\hline
\end{tabular}

$\mathrm{CI}=$ Confidence Interval; SD = Standard Deviation

1 Total numbers may vary due to missing data

${ }^{2}$ Weighted for maternal age, educational level and year of the NINFEA cohort enrolment

${ }^{3}$ Low - primary school or less, medium - secondary school, high - university degree or higher 
Table 2. COVID-19-like symptoms in the 6 weeks after February $21^{\text {st }} 2020$ in the NINFEA population

\begin{tabular}{|c|c|c|c|c|c|c|c|c|}
\hline \multirow{2}{*}{$\begin{array}{c}\text { Symptoms / } \\
\text { COVID-19 test and } \\
\text { diagnosis }\end{array}$} & \multicolumn{2}{|c|}{$\begin{array}{c}\text { Children }<6 \text { years } \\
N=1671\end{array}$} & \multicolumn{2}{|r|}{$\begin{array}{c}\text { Children } \geq 6 \text { years } \\
\mathrm{N}=4064\end{array}$} & \multicolumn{2}{|r|}{$\begin{array}{c}\text { Adults } \\
\mathrm{N}=6133\end{array}$} & \multicolumn{2}{|c|}{$\begin{array}{l}\text { At least one family member } \\
\qquad N=3184\end{array}$} \\
\hline & $\mathrm{N}$ & $\begin{array}{r}\text { Weighted prevalence } \\
(95 \% \mathrm{CI})\end{array}$ & $\mathbf{N}$ & $\begin{array}{r}\text { Weighted prevalence } \\
(95 \% \mathrm{CI})\end{array}$ & $\mathbf{N}$ & $\begin{array}{r}\text { Weighted prevalence } \\
(95 \% \mathrm{CI})\end{array}$ & $\mathrm{N}$ & $\begin{array}{r}\text { Weighted prevalence } \\
(95 \% \mathrm{CI})\end{array}$ \\
\hline Nasal congestion & 259 & $14.9(13.1 ; 17.0)$ & 372 & $9.0(8.1 ; 10.1)$ & 809 & $13.2(12.2 ; 14.2)$ & 831 & $26.0(24.4 ; 27.5)$ \\
\hline Fever $37.0-37.5^{\circ} \mathrm{C}$ & 80 & $4.7(3.7 ; 6.0)$ & 147 & $3.6(3.0 ; 4.3)$ & 397 & $6.6(5.9 ; 7.3)$ & 450 & $14.2(13.0 ; 15.5)$ \\
\hline Fever $>37.5^{\circ} \mathrm{C}$ & 189 & $11.1(9.6 ; 12.9)$ & 299 & $7.3(6.4 ; 8.3)$ & 349 & $5.7(5.1 ; 6.4)$ & 561 & $17.6(16.3 ; 19.0)$ \\
\hline Sore throat & 94 & $5.7(4.5 ; 7.0)$ & 278 & $6.8(5.9 ; 7.7)$ & 892 & $14.5(13.5 ; 15.6)$ & 836 & $26.2(24.6 ; 27.7)$ \\
\hline Cough & 242 & $14.4(12.6 ; 16.5)$ & 351 & $8.7(7.7 ; 9.8)$ & 843 & $13.8(12.8 ; 15.8)$ & 889 & $27.9(26.4 ; 30.0)$ \\
\hline Muscle pain & 32 & $1.9(1.3 ; 2.7)$ & 150 & $3.7(3.1 ; 4.5)$ & 700 & $11.4(10.5 ; 12.4)$ & 597 & $18.8(17.4 ; 20.2)$ \\
\hline Fatigue & 71 & $4.1(3.2 ; 5.3)$ & 230 & $5.6(4.8 ; 6.5)$ & 1020 & $16.5(15.4 ; 17.6)$ & 818 & $25.5(24.0 ; 27.1)$ \\
\hline Nausea/Vomiting & 45 & $2.5(1.9 ; 3.4)$ & 131 & $3.1(2.6 ; 3.8)$ & 178 & $2.9(2.5 ; 3.4)$ & 278 & $8.7(7.8 ; 9.7)$ \\
\hline Diarrhea & 88 & $5.1(4.0 ; 6.3)$ & 202 & $4.8(4.1 ; 5.6)$ & 419 & $6.8(6.1 ; 7.6)$ & 473 & $14.8(13.6 ; 16.1)$ \\
\hline Anosmia/Dysgeusia $^{1}$ & 3 & $0.3(0.1 ; 0.8)$ & 9 & $0.4(0.2 ; 0.8)$ & 95 & $2.4(1.9 ; 3.0)$ & 86 & $4.1(3.3 ; 5.1)$ \\
\hline Breathing difficulties ${ }^{1}$ & 9 & $0.8(0.4 ; 1.5)$ & 18 & $0.7(0.4 ; 1.3)$ & 101 & $2.6(2.1 ; 3.2)$ & 104 & $5.2(4.3 ; 6.3)$ \\
\hline At least one symptom ${ }^{2}$ & 491 & $28.9(26.5 ; 31.5)$ & 973 & $23.6(22.1 ; 25.1)$ & 2275 & $37.0(35.5 ; 38.5)$ & & $55.4(53.7 ; 57,2)$ \\
\hline & & & & & & & 1773 & \\
\hline SARS-CoV-2 test ${ }^{3}$ & 2 & $0.1(0.0 ; 0.4)$ & 12 & $0.3(0.2 ; 0.5)$ & 169 & $2.6(2.2 ; 3.1)$ & 164 & $4.9(4.2 ; 5.7)$ \\
\hline COVID-19 diagnosis & 1 & $0.1(0.0 ; 0.4)$ & 0 & l & 30 & $0.5(0.3 ; 0.7)$ & 27 & $0.8(0.6 ; 1.2)$ \\
\hline
\end{tabular}

$\mathrm{CI}=$ Confidence Interval

${ }^{1}$ Based on 1128 children $<6$ years, 2530 children $\geq 6$ years, 3938 adults and 2044 families

${ }^{2}$ Excluding anosmia/dysgeusia and breathing difficulties

${ }^{3}$ Nasopharyngeal swabs for SARS-CoV-2 testing

Table 3. Geographical correlation between SARS-CoV-2 population cumulative incidence and COVID-19-like symptoms, testing and diagnosis in the NINFEA population

\begin{tabular}{|c|c|c|c|c|c|c|}
\hline \multirow[t]{2}{*}{ Symptoms / SARS-CoV-2 testing and COVID-19 diagnosis } & \multicolumn{2}{|c|}{ Children $\geq 6$ years } & \multicolumn{2}{|l|}{ Adults } & \multicolumn{2}{|c|}{ At least one family member } \\
\hline & Spearman's rho & p-value & Spearman's rho & p-value & Spearman's rho & p-value \\
\hline Nasal congestion & -0.03 & 0.93 & 0.30 & 0.43 & 0.10 & 0.80 \\
\hline Fever $37.0-37.5^{\circ} \mathrm{C}$ & 0.20 & 0.61 & 0.74 & 0.04 & 0.22 & 0.58 \\
\hline Fever $>37.5^{\circ} \mathrm{C}$ & -0.25 & 0.52 & 0.37 & 0.33 & 0.13 & 0.73 \\
\hline Sore throat & 0.23 & 0.55 & 0.47 & 0.21 & 0.65 & 0.06 \\
\hline Cough & 0.43 & 0.24 & 0.25 & 0.52 & -0.02 & 0.97 \\
\hline Muscle pain & 0.70 & 0.04 & 0.88 & 0.002 & 0.97 & 0.00 \\
\hline Fatigue & 0.73 & 0.02 & 0.73 & 0.02 & 0.65 & 0.06 \\
\hline Nausea/Vomiting & -0.20 & 0.61 & 0.12 & 0.77 & 0.38 & 0.31 \\
\hline Diarrhea & 0.08 & 0.83 & 0.32 & 0.41 & 0.05 & 0.90 \\
\hline Anosmia/Dysgeusia & l & l & 0.52 & 0.18 & 0.52 & 0.18 \\
\hline Breathing difficulties & 0.26 & 0.62 & 0.76 & 0.03 & 0.52 & 0.15 \\
\hline At least one symptom ${ }^{1}$ & 0.37 & 0.33 & 0.42 & 0.26 & -0.30 & 0.43 \\
\hline SARS-CoV-2 test ${ }^{2}$ & 0.37 & 0.47 & -0.33 & 0.42 & 0.15 & 0.70 \\
\hline COVID-19 diagnosis & 1 & 1 & 0.80 & 0.20 & 0.80 & 0.20 \\
\hline
\end{tabular}

Provinces with at least 50 participants who responded to the NINFEA questionnaire on COVID-19 were considered: Alessandria, Asti, Arezzo, Cuneo, Florence, Lucca, Milan, Rome, and Turin.

Correlation coefficients of at least 0.70 are reported in bold.

${ }^{1}$ Excluding anosmia/dysgeusia and breathing difficulties

${ }^{2}$ Nasopharyngeal swabs for SARS-CoV-2 testing 


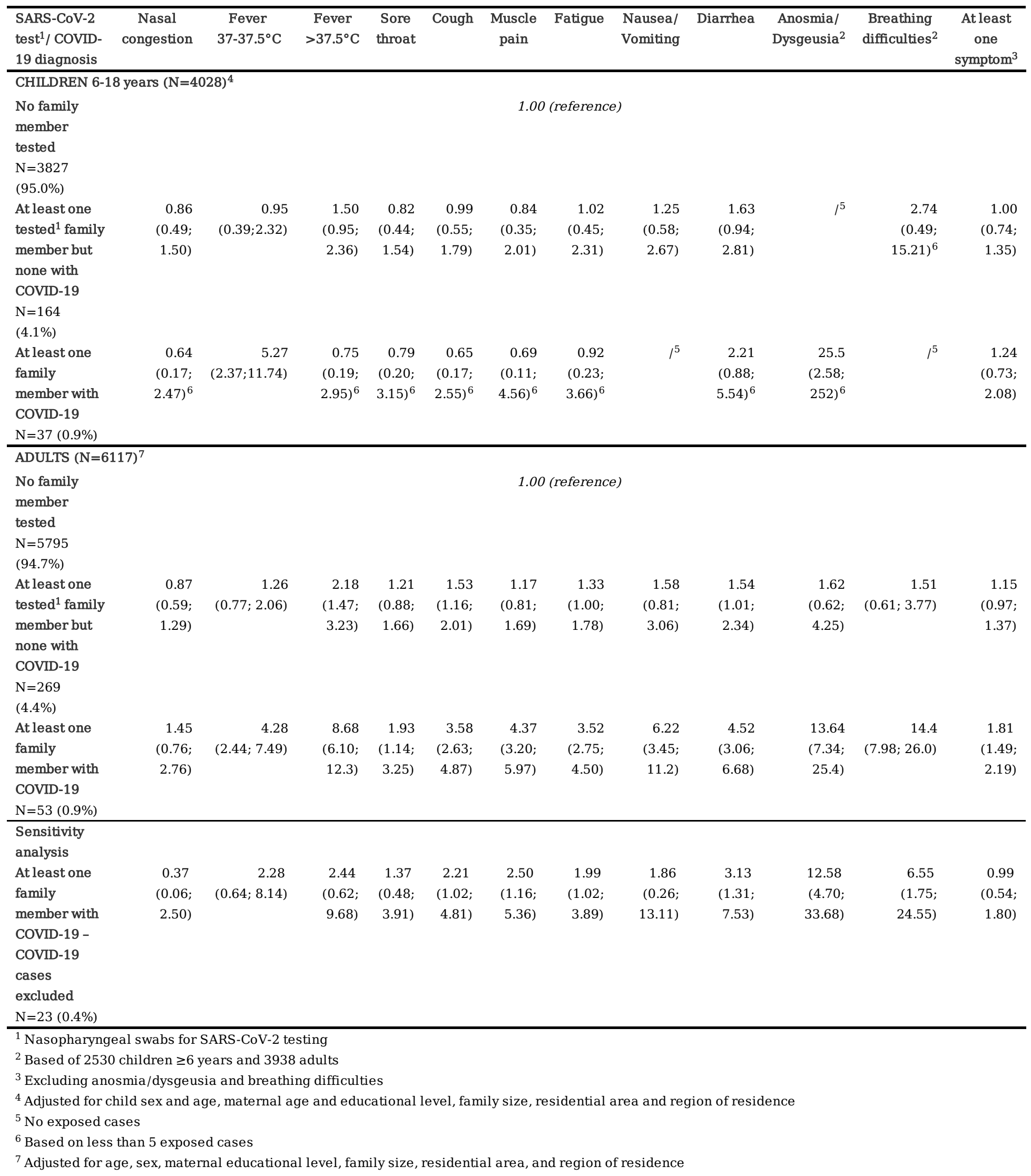

Table 5. Sensitivity, PPVs and NPVs of COVID-19 diagnosis for COVID-19-like symptoms in adults 


\begin{tabular}{|c|c|c|c|c|c|}
\hline Symptoms $^{1}$ & $\begin{array}{c}\text { Sensitivity (95\% } \\
\text { CI) } 2 \text { among NINFEA } \\
\text { participants }\end{array}$ & $\begin{array}{c}\text { PPV }(95 \% \mathrm{CI})^{2} \\
\text { among NINFEA } \\
\text { participants tested } \\
\text { for } \\
\text { SARS-CoV-2 }\end{array}$ & $\begin{array}{c}\text { NPV }(95 \% \mathrm{CI})^{2} \\
\text { among NINFEA } \\
\text { participants tested } \\
\text { for } \\
\text { SARS-CoV-2 } 2^{3}\end{array}$ & $\begin{array}{c}\text { PPV }(95 \% \mathrm{CI})^{2} \\
\text { among NINFEA Piedmont } \\
\text { residents tested for SARS-CoV- } \\
2^{3}\end{array}$ & $\begin{array}{c}\text { PPV }(95 \% \mathrm{CI})^{2} \\
\text { among NINFEA } \\
\text { Piedmont residents }\end{array}$ \\
\hline Nasal congestion & $30.0 \%(13.6 ; 46.4)$ & $32.1 \%(14.8 ; 49.4)$ & $86.5 \%(80.9 ; 92.2)$ & $36.8 \%(15.2 ; 58.5)$ & $1.4 \%(0.4 ; 2.4)$ \\
\hline Fever $37.0-37.5^{\circ} \mathrm{C}$ & $36.7 \%(19.4 ; 53.9)$ & $40.7 \%(22.2 ; 59.3)$ & $88.0 \%(82.7 ; 93.4)$ & $47.1 \%(23.3 ; 70.8)$ & $3.1 \%(1.0 ; 5.3)$ \\
\hline Fever $>37.5^{\circ} \mathrm{C}$ & $70.0 \%(53.6 ; 86.4)$ & $44.4 \%(29.9 ; 59.0)$ & $93.5 \%(89.2 ; 97.9)$ & $51.7 \%(33.5 ; 69.9)$ & $7.3 \%(3.9 ; 10.8)$ \\
\hline Sore throat & $36.7 \%(19.4 ; 53.9)$ & $26.8 \%(13.3 ; 40.4)$ & $86.7 \%(80.8 ; 92.6)$ & $32.1 \%(14.8 ; 49.4)$ & $1.5 \%(0.5 ; 2.5)$ \\
\hline Cough & $60.0 \%(42.5 ; 77.5)$ & $32.1 \%(19.9 ; 44.4)$ & $91.2 \%(85.9 ; 96.4)$ & $36.8 \%(21.5 ; 52.2)$ & $2.6 \%(1.3 ; 4.0)$ \\
\hline Muscle pain & $70.0 \%(53.6 ; 86.4)$ & $42.9 \%(29.0 ; 56.7)$ & $94.2 \%(90.0 ; 98.4)$ & $55.2 \%(37.1 ; 73.3)$ & $3.6 \%(1.9 ; 5.4)$ \\
\hline Fatigue & $80.0 \%(65.7 ; 94.3)$ & $36.5 \%(24.6 ; 48.4)$ & $95.3 \%(91.2 ; 99.3)$ & $43.9 \%(28.7 ; 59.1)$ & $2.9 \%(1.6 ; 4.2)$ \\
\hline Nausea/Vomiting & $30.0 \%(13.6 ; 46.4)$ & $60.0 \%(35.2 ; 84.8)$ & $87.7 \%(82.5 ; 92.9)$ & $60.0 \%(29.6 ; 90.4)$ & $5.4 \%(1.2 ; 9.6)$ \\
\hline Diarrhea & $40.0 \%(22.5 ; 57.5)$ & $35.5 \%(18.6 ; 52.3)$ & $87.7 \%(82.2 ; 93.2)$ & $40.0 \%(18.5 ; 61.5)$ & $3.1 \%(1.0 ; 5.1)$ \\
\hline Breathing difficulties & $57.1 \%(31.2 ; 83.1)$ & $61.5 \%(35.1 ; 88.0)$ & $94.6 \%(89.9 ; 99.2)$ & $88.9 \%(68.4 ; 100.0)$ & $10.8 \%(3.7 ; 17.9)$ \\
\hline Estimated a priori & 1 & $16.6 \%$ & $16.6 \%$ & $18.5 \%$ & $0.54 \%$ \\
\hline COVID-19 prevalence & & & & & \\
\hline
\end{tabular}

${ }^{1}$ Based on 6133 NINFEA participants (3948 among Piedmont residents) for all symptoms but anosmia/dysgeusia and breathing difficulties which estimates are based on 3938 NINFEA participants (2552 from Piedmont).

${ }^{2}$ Wald binomial confidence intervals

${ }^{3}$ Nasopharyngeal swabs for SARS-CoV-2 testing

\section{Supplementary Files}

This is a list of supplementary files associated with this preprint. Click to download.

- AdditionalFile1.docx

- AdditionalFile1.docx 